\title{
Synthesis, Photophysical, Electrochemical and Thermal Studies of Triarylamines based on benzo $[g]$ quinoxalines
}

\author{
AZAM M SHAIKH, BHARAT K SHARMA and RAJESH M KAMBLE* \\ Department of Chemistry, University of Mumbai, Santacruz (East), Mumbai 400 098, India \\ e-mail: kamblerm@chem.mu.ac.in
}

MS received 30 March 2015; revised 29 April 2015; accepted 3 June 2015

\begin{abstract}
A series of novel dipolar and nonplanar compounds featuring electron acceptor benzo[ $g]$ quinoxaline and various electron donor triarylamine units have been synthesized in good yields and fully characterized. The photophysical, electrochemical and thermal properties of the synthesized compounds are described. The photoluminescence properties of the synthesized molecules are influenced by peripheral amines. The derivatives have high Stokes shifts, low band gap and the Commission Internationale de l'Eclairage (CIE) coordinates are positioned in the green-yellow region of the chromaticity diagram. The ionization potentials and electron affinity were found to be in the range of 5.11-5.60 eV and 2.77-2.93 eV and are comparable to the commonly used hole transporters. Thermal studies also reveal that these synthesized molecules have good thermal stability with $5 \%$ and $10 \%$ weight loss temperature ranging from 200 to $355^{\circ} \mathrm{C}$ and 268 to $442^{\circ} \mathrm{C}$, respectively.
\end{abstract}

Keywords. Benzo $[g]$ quinoxaline; triarylamines; green-yellow fluorescent materials; electrochemical; thermal properties.

\section{Introduction}

In last two decades, after the breakthrough work of Tang and Van Slyke, ${ }^{1}$ and Burroughes et al., ${ }^{2}$ extensive investigations have been performed in the development of novel electroluminescent organic materials for organic light emitting devices (OLEDs), ${ }^{3-7}$ Organic field effect transistors $(\mathrm{OFETs})^{8}$ and photovoltaics. ${ }^{9,10}$ Organic $\pi-$ conjugated molecules with donor-acceptor (D-A) system have attracted great attention due to their unique optical and bipolar charge transport properties useful for OLEDs. ${ }^{11,12}$ The electroluminescence (EL) from such D-A molecules basically originate either from excited states of the D or A moiety and intramolecular charge transfer (ICT) excited states ${ }^{13,14}$ or sometimes even from intermolecular excimers or exciplexes. ${ }^{15,16}$ Thus, appropriate selection of the donor-acceptor units allows us to control photoluminescence properties, HOMO-LUMO energy levels and bandgap of the D-A molecules. Many donor-acceptor molecules have been synthesized for electroluminescence devices which include benzimidazole, ${ }^{17,18}$ quinoxaline, ${ }^{19-24}$ indolo[2,3-b]quinoxaline, ${ }^{25}$ polyquinoxaline,${ }^{26}$ pyridoquinoxaline,${ }^{27}$ pyrazinoquinoxaline, ${ }^{28-30}$ etc.

Triarylamine derivatives have been extensively utilized as both hole transporter and emissive material in organic electroluminescent devices using molecules

\footnotetext{
*For correspondence
}

such as anthracene, ${ }^{31,32}$ fluorene, ${ }^{33,34}$ pyrene, ${ }^{35,36}$ carbazole,,$^{37,38}$ dibenzothiophene ${ }^{39}$ since they exhibit low ionization potential, reversible redox potential and bright fluorescence. Further, the triarylamines based on electron-deficient/acceptor units such as benzothiadiazole, ${ }^{40}$ thienopyrazines, ${ }^{41}$ quinoxaline ${ }^{42}$ and oxadiazole $^{43}$ exhibited promising charge (electron and hole) transporting properties which were found to be extremely crucial for the performance of organic electronic devices. In addition to this, their bulky, non-planar structure effectively diminishes the intermolecular $\pi$-stacking in the solid state and enhances thermal stability.

In this work, we have synthesized novel bipolar and nonplanar triarylamines based on benzo[ $g]$ quinoxaline unit and studied their photophysical, electrochemical and thermal properties. The structures of synthesized molecules 2-6 are shown in chart 1.

\section{Experimental}

\subsection{Materials and Methods}

All the starting materials and reagents were purchased from commercial sources (Sigma Aldrich and Alfa Aesar) and were used without any further treatment and purification unless otherwise noted. The organic solvents were of HPLC and spectroscopic grade and 
1572

Azan M Shaikh et al.

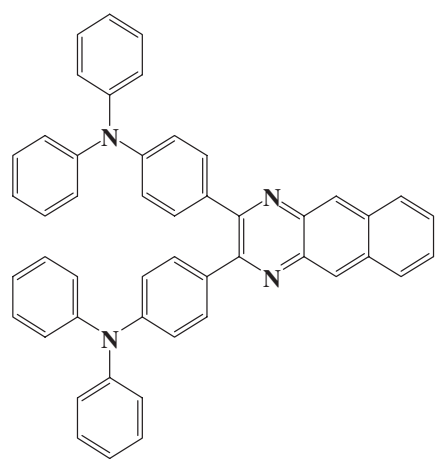

2

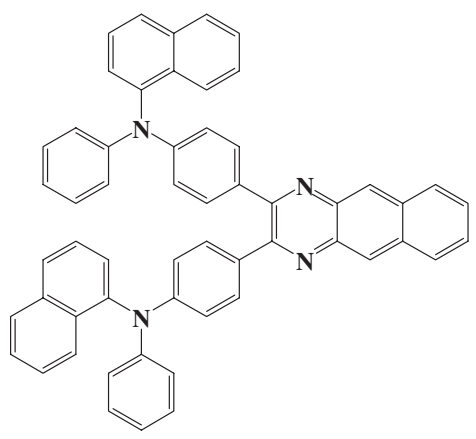

4

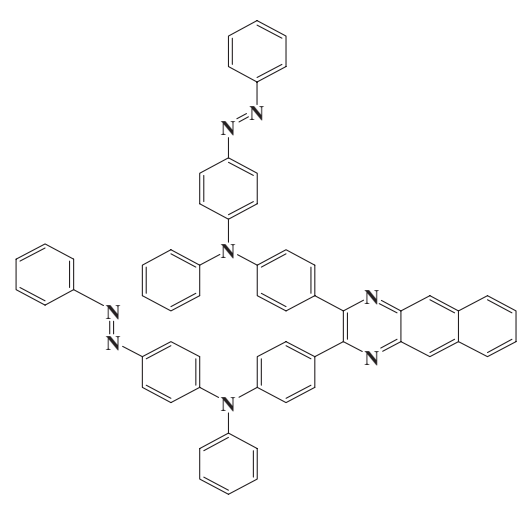

6

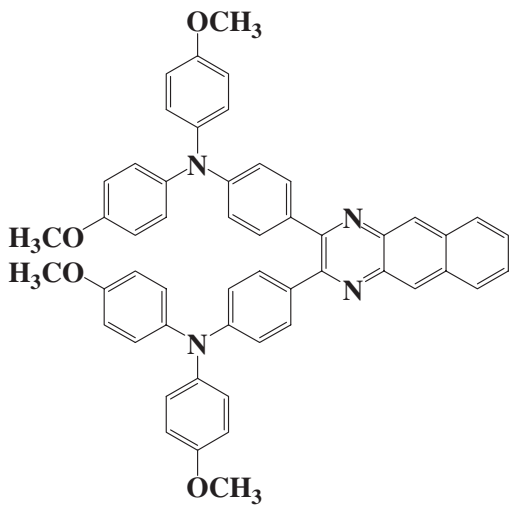

3

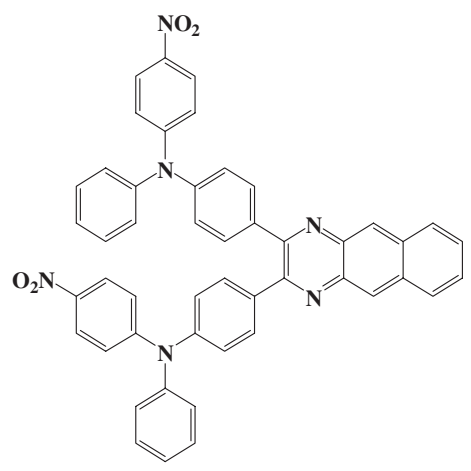

5

Chart 1. Molecular structures of compounds 2-6.

were dried and freshly distilled using the standard procedures ${ }^{44}$ and handled in moisturefree atmosphere. Column chromatography was carried out using SDFine silica gel (60-120 mesh), eluting with n-hexane and chloroform. The progress of reaction and the purity of the compound were checked by thin layer chromatography (TLC) on silica gel coated glass plates, in which the spots were visualized with UV light (365 nm) and in iodine chamber.

Investigation and confirmation of chemical structures of all the synthesized materials were done using HRMS, FT-IR, ${ }^{1} \mathrm{H}$ NMR and ${ }^{13} \mathrm{C}$ NMR and elemental analysis. ${ }^{1} \mathrm{H}$ NMR spectra and ${ }^{13} \mathrm{C}$ NMR spectra were recorded using $\mathrm{CDCl}_{3}$ on a Broker 300 Ultrashield spectrometer 
with Tetramethylsilane (TMS) as internal reference at a working frequency of $300 \mathrm{MHz}$ and $75 \mathrm{MHz}$ respectively. Fourier transform infrared (FT-IR) spectra were recorded on a Perkin Elmer Frontier 91579. The spectra of solid compounds were performed in $\mathrm{KBr}$ pellets. High resolution Mass spectrometric measurements were recorded on maxis impact 282001.00081 instrument using bruker compass data analysis 4.1 and elemental analysis was carried on EA Euro-elemental analysis instrument.

UV-Visible spectra were recorded in $10^{-5} \mathrm{~mol} \mathrm{~L}^{-1}$ solutions in toluene, $\mathrm{CH}_{2} \mathrm{Cl}_{2}$ and $\mathrm{CHCl}_{3}$ in a $1 \mathrm{~cm}$ path length quartz cuvette as well as thermally deposited thin solid films, on SHIMADZU UV-2401PC at room temperature. The excitation and emission spectra were recorded on a Perkin Elmer LS 55 Fluorescence spectrophotometer. Fluorescence quantum yield of the derivatives 2-6 were calculated using tris $(8-$ hydroxyquinolinato)aluminium(III) $\left(\mathrm{Alq}_{3}\right)\left(\phi_{\mathrm{F}}=0.16\right.$ in benzene $)^{45}$ as the standard according to eq. (1).

Quantum efficiency $\phi_{\mathrm{F}}=\phi_{\text {ref }}\left(\frac{\mathrm{S}_{\text {samp }}}{\mathrm{S}_{\text {ref }}}\right)\left(\frac{A_{\text {ref }}}{A_{\text {samp }}}\right)\left(\frac{n_{\text {samp }}^{2}}{n_{\text {ref }}^{2}}\right)$

Where $\mathrm{S}_{\text {ref }}, \mathrm{A}_{\text {ref }}, n_{\text {ref }}$ and $\mathrm{S}_{\text {sample}}, \mathrm{A}_{\text {sample }}, n_{\text {sample }}$ represent the integrated emission band area, the absorbance at the excited wavelength, and the refractive index of the solvent, respectively for the standard reference and the sample. The Stokes shifts were also determined and shown in table 2.

Cyclic voltammetry studies was carried out on a computer controlled AUTOLAB PGSTATE 30 electrochemical analyzer equipped with USB electro chemical interface using GPES software version 4.9.005. Typically, a three electrode cell equipped with a glassy carbon working electrode, $\mathrm{Ag} / \mathrm{AgCl}$ (non-aqueous) reference electrode and platinum $(\mathrm{Pt})$ wire as counter electrode was employed. The measurements have been carried at room temperature in anhydrous acetonitrile with tetrabutyl ammonium hexafluoro phosphate solution $(0.1 \mathrm{M})$ as supporting electrolyte with a scan rate of $100 \mathrm{mVs}^{-1}$. The potential of $\mathrm{Ag} / \mathrm{AgCl}$ reference electrode was calibrated by using ferrocene/ferrocenium redox couple which has the known oxidation potential of $+4.8 \mathrm{eV}^{46}$

Melting points of the products were less approximately determined by open capillary method. The thermo gravimetric analysis (TGA) and Differential thermal analysis (DTA) were performed using Perkin Elmer Pyris Diamond TG/DTA under nitrogen atmosphere.

\subsection{Synthesis of the compounds 2-6}

The synthetic protocol used for the preparation of compounds 1-6 is shown in scheme 1. The detailed synthetic procedure and characterization data of compounds 1-6 are given below.

\section{2a 2,3-Bis(4-bromophenyl)benzo[g]quinoxaline (1):} A mixture of 4,4'-dibromobenzil $(3.680 \mathrm{~g}, 10 \mathrm{mmol})$ and 2,3-diaminonaphthalene $(1.582 \mathrm{~g}, 10 \mathrm{mmol})$ was dissolved in $20 \mathrm{~mL}$ of glacial acetic acid and refluxed for $3 \mathrm{~h}$. The reaction mixture was allowed to cool and then poured over crushed ice to obtain the light green coloured solid. The obtained solid was then dried under vacuum and purified using column chromatography (eluent: $\mathrm{n}$-hexane: chloroform ratio as 70:30) to obtain a bright green solid. Yield: $4.429 \mathrm{~g}$ (90.4\%), M.p.: $208^{\circ} \mathrm{C}$. IR (KBr $\left.v_{\max } \mathrm{cm}^{-1}\right): 3056,2922$,

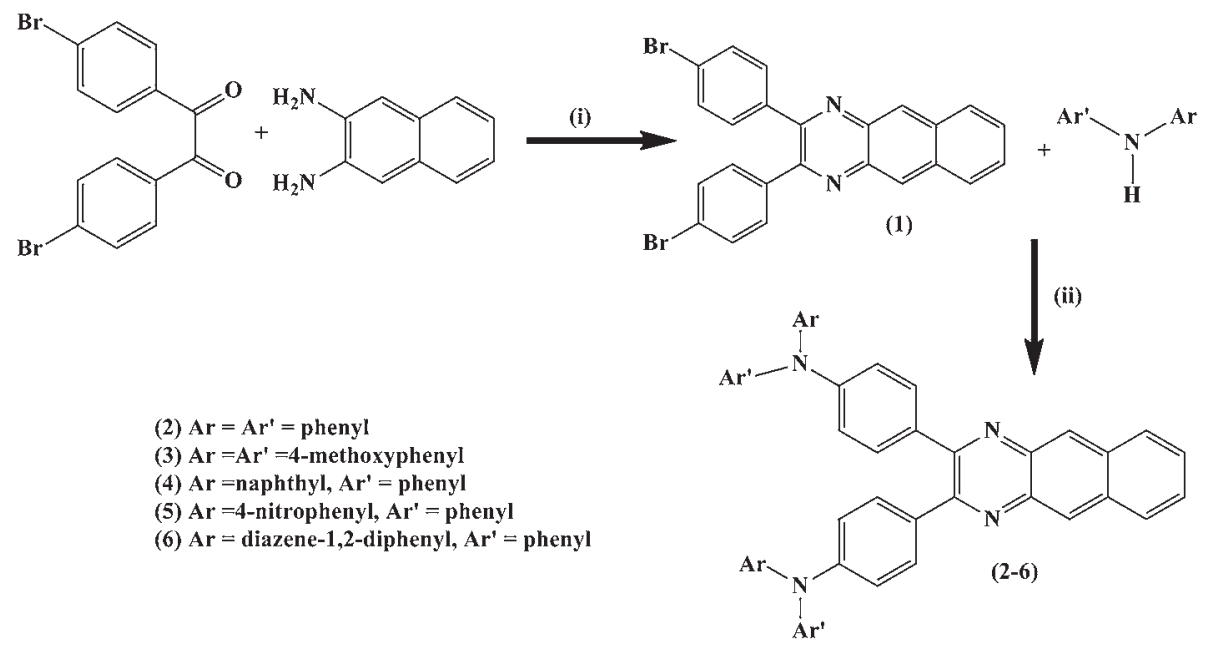

Scheme 1. Synthesis of compounds 2-6. Reaction conditions: (i) gl. $\mathrm{CH} 3 \mathrm{COOH}$, Reflux, 3 h; (ii) Pd2(dba) 3 , SPhos, t-BuONa, Reflux, $\mathrm{N}_{2}$ atmosphere, $4-10 \mathrm{~h}$. 
2852, $1585(-\mathrm{C}=\mathrm{N}$ str $), 1068 ;{ }^{1} \mathrm{H}$ NMR $(300 \mathrm{MHz}$, $\left.\mathrm{CDCl}_{3}\right): \delta(\mathrm{ppm}) 8.70(\mathrm{~s}, 2 \mathrm{H}, \mathrm{ArH}), 8.10(\mathrm{dd}, 2 \mathrm{H}$, $\mathrm{ArH}, J=3.3,3.0 \mathrm{~Hz}), 7.41-7.58(\mathrm{~m}, 10 \mathrm{H}, \mathrm{ArH}$,$) ;$ ${ }^{13} \mathrm{C}$ NMR: $152.46,137.77,137.72,134.23,131.61$, 131.38, 128.53, 127.60, 126.96, 123.89. Anal.Calcd for $\mathrm{C}_{24} \mathrm{H}_{14} \mathrm{Br}_{2} \mathrm{~N}_{2}$ : C (58.81), H (2.88), N (5.71), $\mathrm{Br}$ (32.60). Found: C (58.79), H (2.86), N (5.74), Br (32.61).

$2.2 \mathrm{~b}$ 2,3-Bis[4-(N-phenylbenzeamino)phenyl]benzo[g] quinoxaline (2): A mixture of compound 1 (490 mg, $1 \mathrm{mmol}$ ) and diphenylamine $(338 \mathrm{mg}, 2 \mathrm{mmol}$ ) was dissolved in anhydrous toluene $(20 \mathrm{~mL})$. To this solution $\mathrm{Pd}_{2}(\mathrm{dba})_{3}$ ( $37 \mathrm{mg}, 0.04 \mathrm{mmol}$ ), SPhos (25 mg, $0.06 \mathrm{mmol}$ ) and $\mathrm{t}-\mathrm{BuONa}(300 \mathrm{mg}, 3.1 \mathrm{~mol})$ were added. The reaction mixture was continuously stirred under nitrogen atmosphere at $100^{\circ} \mathrm{C}$ for $4 \mathrm{~h}$. Reaction mixture was then cooled to room temperature and extracted with chloroform. The solid thus obtained was then purified by column chromatography (eluent: $n$-hexane) to obtain a bright yellow solid. Yield: $614 \mathrm{mg}$ (92.0\%), M.p.: $249^{\circ} \mathrm{C}$. IR $\left(\mathrm{KBr}_{\max } \mathrm{cm}^{-1}\right): 3037,2922,2852,1585$ $(-\mathrm{C}=\mathrm{N}$ str $), 1485,1270 \quad(-\mathrm{C}-\mathrm{N}$ str $) ;{ }^{1} \mathrm{H}$ NMR $\left(300 \mathrm{MHz}, \mathrm{CDCl}_{3}\right): \delta$ (ppm) 8.78 (s, 2H, ArH), 8.15 (dd, $2 \mathrm{H}, \operatorname{ArH}, J=3.3 \mathrm{~Hz}), 7.50-7.57$ (m, 6H, ArH), 7.25-7.31(m, 8H, ArH), 7.03-7.25 (m, 16H, ArH); ${ }^{13} \mathrm{C}$ NMR: 153.76, 148.90, 147.18, 137.58, 133.93, 132.02, $130.92,129.39,128.50,126.98,126.61,125.12$, 123.63, 121.78; HRMS calcd for $\mathrm{C}_{48} \mathrm{H}_{35} \mathrm{~N}_{4}$ 667.2856, found 667.2851. Anal.Calcd for $\mathrm{C}_{48} \mathrm{H}_{34} \mathrm{~N}_{4}$ : C (86.46), H (5.14), N (8.40). Found: C (86.44), H (5.13), N (8.44).

2.2c 2,3-Bis[4-(4-methoxy-N-(4-)benzeamino)phenyl] benzo[g]quinoxaline (3): A mixture of compound $\mathbf{1}$ (490 mg, $1 \mathrm{mmol}$ ) and 4,4'-dimethoxydiphenyl amine (462 mg, $2 \mathrm{mmol}$ ) was dissolved in anhydrous toluene $(20 \mathrm{~mL})$. To this solution $\mathrm{Pd}_{2}(\mathrm{dba})_{3}(37 \mathrm{mg}, 0.04 \mathrm{mmol})$, SPhos (25 mg, $0.06 \mathrm{mmol}$ ) and t-BuONa $(300 \mathrm{mg}$, $3.1 \mathrm{~mol}$ ) were added. The reaction mixture was continuously stirred under nitrogen atmosphere at $100^{\circ} \mathrm{C}$ for $6 \mathrm{~h}$. Reaction mixture was then cooled to room temperature and extracted with chloroform. The solid thus obtained was then purified by column chromatography (eluent: $\mathrm{n}$-hexane: chloroform ratio as 70:30) to obtain a bright red solid. Yield: $760 \mathrm{mg}(96.0 \%)$, M.p.: $263^{\circ} \mathrm{C}$. IR $\left(\mathrm{KBr}_{\max } \mathrm{cm}^{-1}\right): 3040,2923,2834,1591(-\mathrm{C}=\mathrm{N}$ str), 1235 (-C-N str) ; ${ }^{1} \mathrm{H}$ NMR $\left(300 \mathrm{MHz}, \mathrm{CDCl}_{3}\right)$ : $\delta(\mathrm{ppm}) 8.65$ (s, 2H, ArH), 8.03 (dd, 2H, ArH, $J=$ 3.3, 3.0 Hz), 7.44-7.52 (m, 6H, ArH), 7.07-7.12(m, $8 \mathrm{H}, \mathrm{ArH}), 6.83-6.90(\mathrm{~m}, 12 \mathrm{H}, \mathrm{ArH}), 3.80$ (s 12H, $\left.-\mathrm{OCH}_{3}\right) ;{ }^{13} \mathrm{C}$ NMR:156.30, 154.02, 149.60, 140.30, $137.80,133.77,130.74,130.55,128.44,127.11$,
126.85, 126.35, 118.92, 114.77, 55.48; HRMS calcd for $\mathrm{C}_{52} \mathrm{H}_{43} \mathrm{~N}_{4} \mathrm{O}_{4}$ 787.3201, found 787.3206. Anal.Calcd for $\mathrm{C}_{52} \mathrm{H}_{42} \mathrm{~N}_{4} \mathrm{O}_{4}$ : C (79.37), $\mathrm{H}$ (5.38), $\mathrm{N}$ (7.12), O (8.13). Found: C (79.35), H (5.36), N (7.15), O (8.14).

\section{2d 2,3-Bis[4-(N-phenyl-2-naphthylamino)phenyl]} benzo[g]quinoxaline (4): A mixture of compound $\mathbf{1}$ (490 mg, $1 \mathrm{mmol}$ ) and $\mathrm{N}$-naphthylphenylamine (438 mg, $2 \mathrm{mmol})$ was dissolved in anhydrous toluene $(20 \mathrm{~mL})$. To this solution $\mathrm{Pd}_{2}(\mathrm{dba})_{3}(37 \mathrm{mg}, 0.04 \mathrm{mmol})$, SPhos $(25 \mathrm{mg}, 0.06 \mathrm{mmol})$ and $\mathrm{t}-\mathrm{BuONa}(300 \mathrm{mg}, 3.1 \mathrm{~mol})$ were added. The reaction mixture was continuously stirred under nitrogen atmosphere at $100^{\circ} \mathrm{C}$ for $5 \mathrm{~h}$. Reaction mixture was then cooled to room temperature and extracted with chloroform. The solid thus obtained was then purified by column chromatography eluent: n-hexane: chloroform ratio as 80:20 to obtain a bright yellow solid. Yield: $722 \mathrm{mg}(94.0 \%)$, M.p.: $342^{\circ} \mathrm{C}$. IR $\left(\mathrm{KBr} v_{\max } \mathrm{cm}^{-1}\right): 3044,2922,1587(-\mathrm{C}=\mathrm{N}$ str $), 1267$ $\left(-\mathrm{C}-\mathrm{N}\right.$ str); ${ }^{1} \mathrm{H}$ NMR $\left(300 \mathrm{MHz}, \mathrm{CDCl}_{3}\right): \delta$ (ppm) 8.64 (s, 2H, ArH), 8.02 (dd, 2H, ArH, $J=3.3,3.0 \mathrm{~Hz}$ ), 7.76-7.86 (m, 6H, ArH), 6.87-7.50 (m, 26H, ArH); ${ }^{13} \mathrm{C}$ NMR: 153.94, 149.31, 147.63, 143.00, 137.85, 135.30, $133.82,131.50,131.06,130.84,129.23,128.44$, $128.40,127.29,127.01,126.81,126.43,126.29$, 126.21, 124.13, 123.16, 122.78, 119.88; HRMS calcd for $\mathrm{C}_{56} \mathrm{H}_{39} \mathrm{~N}_{4}$ 767.3169, found 767.3172. Anal.Calcd for $\mathrm{C}_{56} \mathrm{H}_{38} \mathrm{~N}_{4}$ : C (87.70), $\mathrm{H}$ (4.99), N (7.31). Found: $\mathrm{C}$ (87.72), H (4.96), N (7.32).

2.2e 2,3-Bis[4-(4-nitro-N-phenylbenzeamino)phenyl] benzo[g]quinoxaline (5): A mixture of compound $\mathbf{1}$ (490 mg, $1 \mathrm{mmol})$ and 4-nitrodiphenylamine (472 mg, $2 \mathrm{mmol}$ ) was dissolved in anhydrous toluene $(20 \mathrm{~mL})$. To this solution $\mathrm{Pd}_{2}(\mathrm{dba})_{3}(37 \mathrm{mg}, 0.04 \mathrm{mmol})$, SPhos $(25 \mathrm{mg}, 0.06 \mathrm{mmol})$ and $\mathrm{t}-\mathrm{BuONa}(300 \mathrm{mg}, 3.1 \mathrm{~mol})$ were added. The reaction mixture was continuously stirred under nitrogen atmosphere at $100^{\circ} \mathrm{C}$ for $10 \mathrm{~h}$. Reaction mixture was then cooled to room temperature and extracted with chloroform. The solid thus obtained was then purified by column chromatography (eluent: n-hexane: chloroform ratio as 60:40) to obtain a bright yellow solid. Yield: $210 \mathrm{mg}$ (53.17\%), M.p.: $314^{\circ} \mathrm{C}$. IR $\left(\mathrm{KBr}_{\max } \mathrm{cm}^{-1}\right): 3051,2921,1580(-\mathrm{C}=\mathrm{N})$, 1489, 1286 (-C-N str), 1108; ${ }^{1} \mathrm{H}$ NMR $(300 \mathrm{MHz}$, $\left.\mathrm{CDCl}_{3}\right): \delta(\mathrm{ppm}) 8.89(\mathrm{~s}, 2 \mathrm{H}, \mathrm{ArH}), 8.18(\mathrm{dd}, 2 \mathrm{H}$, $\mathrm{ArH}, J=3.3,3.0 \mathrm{~Hz}), 8.08(\mathrm{~d}, 4 \mathrm{H}, \mathrm{ArH}, J=9.3$ $\mathrm{Hz}$ ), $7.62(\mathrm{~d}, 6 \mathrm{H}, \mathrm{ArH}, J=6.6 \mathrm{~Hz}), 7.03-7.42(\mathrm{~m}$, $18 \mathrm{H}, \mathrm{ArH}) ;{ }^{13} \mathrm{C}$ NMR: $152.72,147.52,145.33,141.30$, $134.54,131.72,130.21,128.69,127.62,126.83$, 126.36, 125.47, 124.59, 120.05; HRMS calcd for $\mathrm{C}_{48} \mathrm{H}_{33} \mathrm{~N}_{6} \mathrm{O}_{4}$ 757.2558, found 757.2577. Anal.Calcd for 
$\mathrm{C}_{48} \mathrm{H}_{32} \mathrm{~N}_{6} \mathrm{O}_{4}$ : C (76.17), H (4.25), N (8.46), O (11.10). Found: C (76.17), H (4.23), N (8.49), O (11.12).

\section{$2.2 \mathrm{f} \quad$ 2,3-Bis[4-(N-pheny-4-(2- phenyldiazenyl)benzea-} mino)phenyl]benzo[g]quinoxaline (6): A mixture of compound 1 (490 mg, $1 \mathrm{mmol}$ ) and 4-(phenylazo)diphenylamine $(592 \mathrm{mg}, 2 \mathrm{mmol}$ ) was dissolved in anhydrous toluene $(20 \mathrm{~mL})$. To this solution $\operatorname{Pd}_{2}(\mathrm{dba})_{3}(37 \mathrm{mg}$, $0.04 \mathrm{mmol}$ ), SPhos) (25 mg, $0.06 \mathrm{mmol}$ ) and t-BuONa $(300 \mathrm{mg}, 3.1 \mathrm{~mol})$ were added. The reaction mixture was continuously stirred under nitrogen atmosphere at $100^{\circ} \mathrm{C}$ for $7 \mathrm{~h}$. Reaction mixture was then cooled to room temperature and extracted with chloroform. The solid thus obtained was then purified by column chromatography (eluent: $\mathrm{n}$-hexane: chloroform ratio as 65:35) to obtain red solid. Yield: $401 \mathrm{mg}$ (56.0\%), M.p.: $225^{\circ} \mathrm{C}$. IR $\left(\mathrm{KBr}_{\max } \mathrm{cm}^{-1}\right)$ : 3036, 2922, 2855, $1585(-\mathrm{C}=\mathrm{N}$ str $) 1489,1269(-\mathrm{C}-\mathrm{N}$ str $) ;{ }^{1} \mathrm{H}$ NMR $\left(300 \mathrm{MHz}, \mathrm{CDCl}_{3}\right): \delta$ (ppm) $8.77(\mathrm{~s}, 2 \mathrm{H}, \mathrm{ArH}), 8.10$ $(\mathrm{dd}, 2 \mathrm{H}, \operatorname{ArH}, J=3.3,3.0 \mathrm{~Hz}), 7.84-7.89(\mathrm{~m}, 8 \mathrm{H}$, ArH), 7.15-7.59(m, 30H, ArH); ${ }^{13} \mathrm{C}$ NMR: 153.37, $152.80,149.84,148.20,147.91,146.46,137.40$, $134.11,133.16,131.20,130.42,129.74,129.03$, $128.56,127.09,126.05,124.84,124.35,123.36$, 123.09, 122.61; HRMS calcd for $\mathrm{C}_{60} \mathrm{H}_{43} \mathrm{~N}_{8}$ 875.3605, found 875.3596. Anal.Calcd for $\mathrm{C}_{60} \mathrm{H}_{42} \mathrm{~N}_{8}$ : C (82.36), H (4.84), N (12.81). Found: C (82.33), H (4.89), N (12.78).

\section{Results and Discussion}

\subsection{Synthesis and characterization}

2,3-Bis(4-bromophenyl)benzo[ $g$ ]quinoxaline (1) was prepared by condensing 4,4'-dibromobenzil and 2,3-diaminonaphthalene in glacial acetic acid. Compounds 2-6 were synthesized by using palladium catalyzed BuchwaldHartwig amination reaction ${ }^{47,48}$ by treating compound 1 with the corresponding diarylamine in the presence of tris(dibenzylideneacetone)dipalladium $\left(\mathrm{Pd}_{2}(\mathrm{dba})_{3}\right)$, 2-dicyclohexylphoshpino-2', 6'-dimethoxybiphenyl (SPhos) and sodium tertiarybutoxide(t-BuONa) in toluene. For the synthesis of compounds 2-6 we have also tried other catalyst combinations such as $\mathrm{Pd}(\mathrm{OAc})_{2} / \mathrm{XantPhos}, \mathrm{Pd}$ $(\mathrm{dba})_{2} /$ XantPhos, Pd(dba $)_{2} /$ DPPF and found that they worked equally well. However, the use of $\operatorname{Pd}_{2}(\mathrm{dba})_{3} /$ SPhos catalyst combination significantly reduces the reaction time with good yield as compared to the above three combinations. The synthesized compounds 2-6 are yellow to red solid soluble in common organic solvents including dichloromethane, toluene, chloroform, acetonitrile, etc. However, they are sparingly soluble in methanol and insoluble in water. All the target compounds were confirmed by FT-IR, ${ }^{1} \mathrm{H},{ }^{13} \mathrm{C} \mathrm{NMR}$, high resolution mass spectroscopy and elemental analysis.

\subsection{Photophysical properties}

The absorption and fluorescence properties of compounds 2-6 were studied in solvents of varying polarity (toluene, dichloromethane and chloroform) and solid thin film. The synthesized molecules show similar UVVis absorption spectra in all three solvents and thin solid film (figure 1a). The absorption spectra of all the synthesized molecules in the above mentioned solvents and thin solid film reveal two major bands arising due to $\pi-\pi^{*}(300-315 \mathrm{~nm})$ transition within the arylamine units and the benzo[ $g]$ quinoxaline core and lower energy charge transfer transition $(407-495 \mathrm{~nm})$ from various electron donor triarylamines to electron acceptor benzo $[g]$ quinoxaline segment. In addition, an $\mathrm{n}-\pi^{*}$ transition originating from the terminal arylamine moiety is expected to appear below $300 \mathrm{~nm}$, but it is probably overlapping with the intense $\pi-\pi^{*}$ transitions.

Further, in the absorption spectra of compounds 5 and $\mathbf{6}$ (figure 1a) in above mentioned solvents and solid thin film, the intensity of charge transfer transition $(407-450 \mathrm{~nm})$ is high as compared to other derivatives suggesting better charge transfer due to electron withdrawing group like $-\mathrm{NO}_{2}$ and diazene group on triarylamine moiety.

The emission peaks of compounds $\mathbf{2 - 6}$ in the toluene are in the range of $510-555 \mathrm{~nm}$ (figure $1 \mathrm{~b}$ ) with a bathochromic shift as the thin film ranging from 532$596 \mathrm{~nm}$ (see supplementary information). A significant bathochromic shift of $41 \mathrm{~nm}$ is observed in solid thin film of compound $\mathbf{2}$ as compared to toluene due to electron donating methoxy group on triarylamine moiety. The emission intensity of compound $\mathbf{6}$ in toluene is too low which may,due to presence of diazene group on triarylamine moiety and thus showing influence of peripheral amine on emission intensity. On increasing polarity of solvent from toluene to $\mathrm{CH}_{2} \mathrm{Cl}_{2}$ and $\mathrm{CHCl}_{3}$, compounds 2 and 4 emit with red shift of around 44$61 \mathrm{~nm}$. However compound 3, 5 and $\mathbf{6}$ do not emit in $\mathrm{CH}_{2} \mathrm{Cl}_{2}$ and $\mathrm{CHCl}_{3}$ suggesting nonradiative relaxation from excited state to ground state in polar solvents.

The colour quality of the emitted light is adjudged by means of Commission International de l'Eclairage (CIE) coordinates. The CIE chromaticity coordinates were determined by using emission spectra of compounds 2-6 excited at $550 \mathrm{~nm}$ in solid thin film. The 


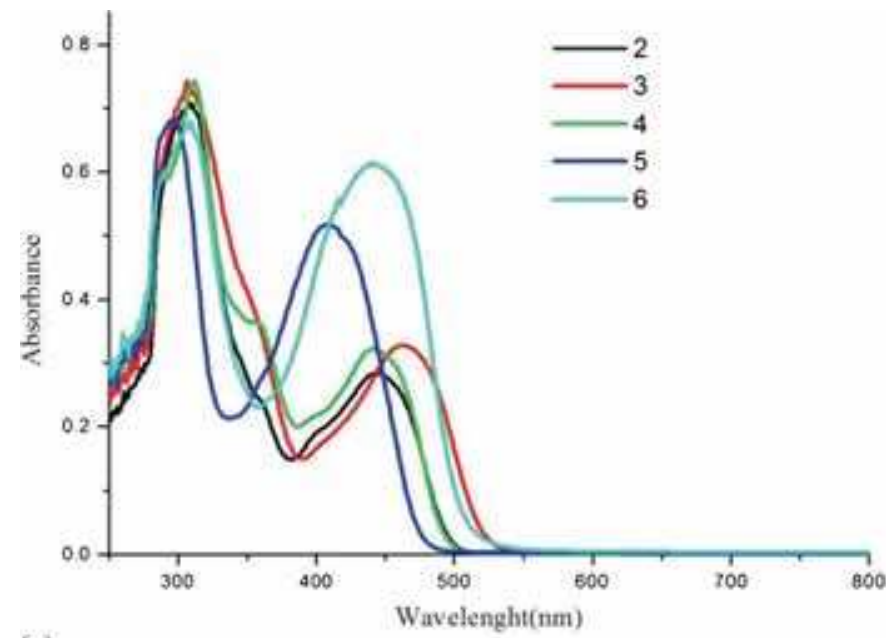

(a)

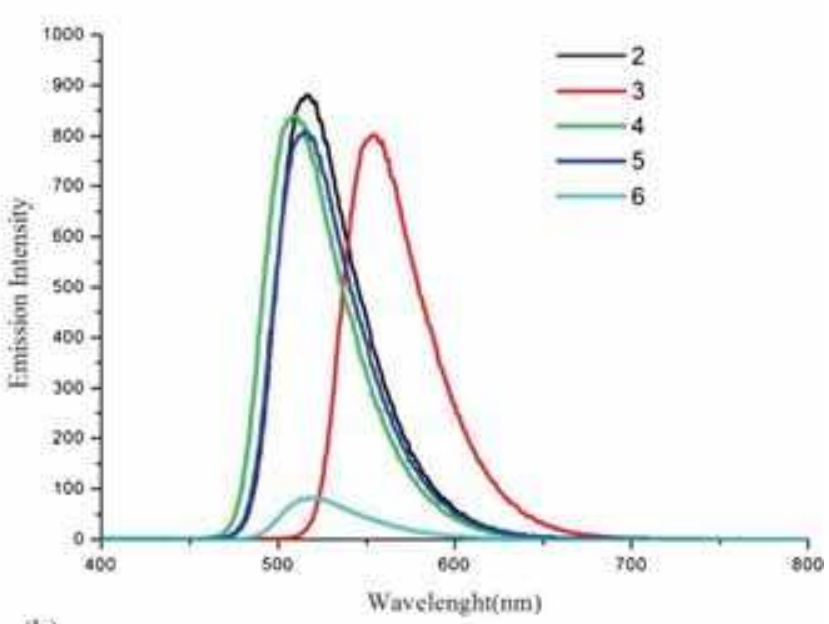

(b)

Figure 1. UV-Vis absorption spectra (a) and emission spectra; (b) of compounds 2-6 in toluene. (see supplementary information for spectra in $\mathrm{CH}_{2} \mathrm{Cl}_{2}, \mathrm{CHCl}_{3}$ and solid thin film).

obtained CIE coordinates are located in green-yellow region (see supplementary information).

Other basic photophysical characteristics such as the molar extinction coefficient $(\log \varepsilon)$, optical band gaps $\left(\mathrm{E}_{\mathrm{g}}^{\mathrm{opt}}\right)$, Stokes shift $\left(v_{\mathrm{Abs}}-v_{\mathrm{Em}}\right)$ and fluorescent quantum yield $\left(\phi_{\mathrm{F}}\right)$ of the molecules were determined and summarized in tables 1 and 2.

\subsection{Electrochemical properties}

Electrochemical property of the synthesized derivatives was measured by cyclic voltammetry in dichloromethane solution using ferrocene as an internal standard to calibrate the redox potentials. On anodic sweep, two quasi-reversible waves were observed for all the synthesized compounds 2-6 (figures $2 \mathrm{a}$ and $2 \mathrm{~b}$ ) which may be due to the oxidation of triarylamine moiety corresponding to two electrons. ${ }^{49} \mathrm{E}_{\mathrm{ox}}$ potential decreases on increasing donor strength $(3>\mathbf{4}>\mathbf{2})$.

On cathodic sweep, one reversible wave was observed for all the compounds (see supplementary information) corresponding to the reduction of benzo[g]quinoxaline segment. ${ }^{50}$ On cathodic sweep an irreversible wave was observed for compound $\mathbf{5}$ at $-1.30 \mathrm{~V}$ which may be due to the reduction of $-\mathrm{NO}_{2}$ group.

The HOMO and LUMO energy levels of the synthesized materials 2-6 are in the range of $5.11-5.60 \mathrm{eV}$ and $2.77-2.93 \mathrm{eV}$, respectively which are comparable to the commonly used triarylamines based hole transporting materials such as N,N'-(3-methylphenyl)-1,1'biphenyl-4,4'-diamine (TPD) $(\mathrm{HOMO}=-5.50 \mathrm{eV}$ and LUMO $=-2.3 \mathrm{eV}$ ) and N,N'-Di(1-naphthyl)$\mathrm{N}, \mathrm{N}$ '-diphenyl(1,1'-biphenyl)-4,4'-diamine $(\alpha$-NPD) $(\mathrm{HOMO}=-5.50 \mathrm{eV}$ and $\mathrm{LUMO}=-2.4 \mathrm{eV})$. Thus, the synthesized molecules might act as hole transporting materials. The energy band gap calculated from the cyclic voltammetry measurements are in range of 2.25$2.82 \mathrm{eV}$ which are in close agreement with optical band gap. The observed parameters are reported in table 3.

\subsection{Thermal properties}

The thermal stability of the synthesized molecules 2-6 (table 3) was determined by Thermogravimetric

Table 1. Absorption and Emission data of compounds 2-6.

\begin{tabular}{|c|c|c|c|c|c|c|c|c|c|}
\hline \multirow[b]{2}{*}{ Compd. } & \multicolumn{4}{|c|}{$\lambda_{\mathrm{abs}}(\mathrm{nm})^{\mathrm{a}}$} & \multicolumn{4}{|c|}{$\lambda_{\mathrm{em}}(\mathrm{nm})^{\mathrm{b}}$} & \multirow[b]{2}{*}{$\log \varepsilon^{t}$} \\
\hline & toluene & $\mathrm{CH}_{2} \mathrm{Cl}_{2}$ & $\mathrm{CHCl}_{3}$ & film & toluene & $\mathrm{CH}_{2} \mathrm{Cl}_{2}$ & $\mathrm{CHCl}_{3}$ & film & \\
\hline 2 & 308,443 & 304,445 & 310,452 & 308,449 & 517 & 578 & 568 & 532 & 4.853 \\
\hline 3 & 306,463 & 306,464 & 300,470 & $293,358,495$ & 555 & & & 596 & 4.863 \\
\hline 4 & 312,441 & 310,446 & 312,449 & 315,446 & 510 & 569 & 554 & 551 & 4.873 \\
\hline 5 & 297,407 & 297,415 & 300,416 & 298,429 & 516 & & & 539 & 4.835 \\
\hline 6 & 309,439 & 306,439 & 308,445 & 305,450 & 520 & & & 540 & 4.831 \\
\hline
\end{tabular}

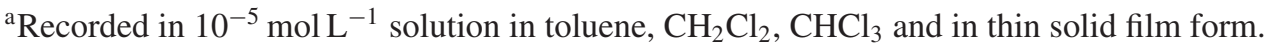

${ }^{\mathrm{b}} \varepsilon$ is Extinction coefficient $\left(\mathrm{L} \mathrm{mol}^{-1} \mathrm{~cm}^{-1}\right)$ measured in toluene. 
Table 2. Optical bandgap, Stoke shift, Quantum yield and CIE Coordinates for compounds 2-6.

\begin{tabular}{|c|c|c|c|c|c|c|}
\hline \multirow[b]{2}{*}{ Compd } & \multirow{2}{*}{$\begin{array}{c}E_{g}^{o p t}(\mathrm{eV})^{\mathrm{a}} \\
\quad \text { film }\end{array}$} & \multicolumn{2}{|c|}{ Stokes shift $\left(\mathrm{cm}^{-1}\right)^{b}$} & \multirow[t]{2}{*}{$\phi_{\mathrm{F}}^{\mathrm{c}}$} & \multicolumn{2}{|c|}{ CIE coordinates ${ }^{\mathrm{d}}$} \\
\hline & & toluene & film & & $\mathrm{x}$ & $\mathrm{y}$ \\
\hline 2 & 2.39 & 13125 & 13492 & 0.40 & 0.364 & 0.409 \\
\hline 3 & 2.30 & 14661 & 16778 & 0.59 & 0.427 & 0.378 \\
\hline 4 & 2.42 & 12443 & 13597 & 0.45 & 0.432 & 0.465 \\
\hline 5 & 2.43 & 14290 & 15004 & 0.38 & 0.398 & 0.463 \\
\hline 6 & 2.45 & 13131 & 13918 & 0.04 & 0.393 & 0.405 \\
\hline
\end{tabular}

${ }^{a}$ Optical bandgap estimated from the optical edge of spectrum in thin solid film.

$$
E_{g}^{o p t}=\left(\frac{1240.8}{\lambda_{\text {opt edge }}}\right) \mathrm{eV}
$$

${ }^{\mathrm{b}}$ Stokes shift calculated from absorption and emission wavelengths observed in solution and thin solid film.

${ }^{\mathrm{c}}$ Quantum yield with reference to $\mathrm{Alq}_{3}\left(\phi_{\mathrm{F}}=0.16\right.$ in benzene). ${ }^{45}$

${ }^{\mathrm{d}}$ Measured in solid thin film.

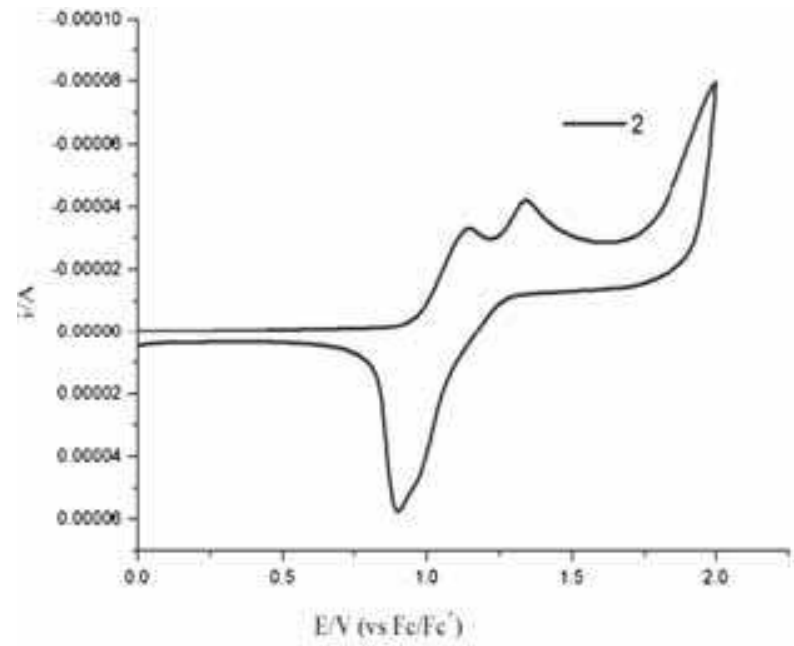

(a)

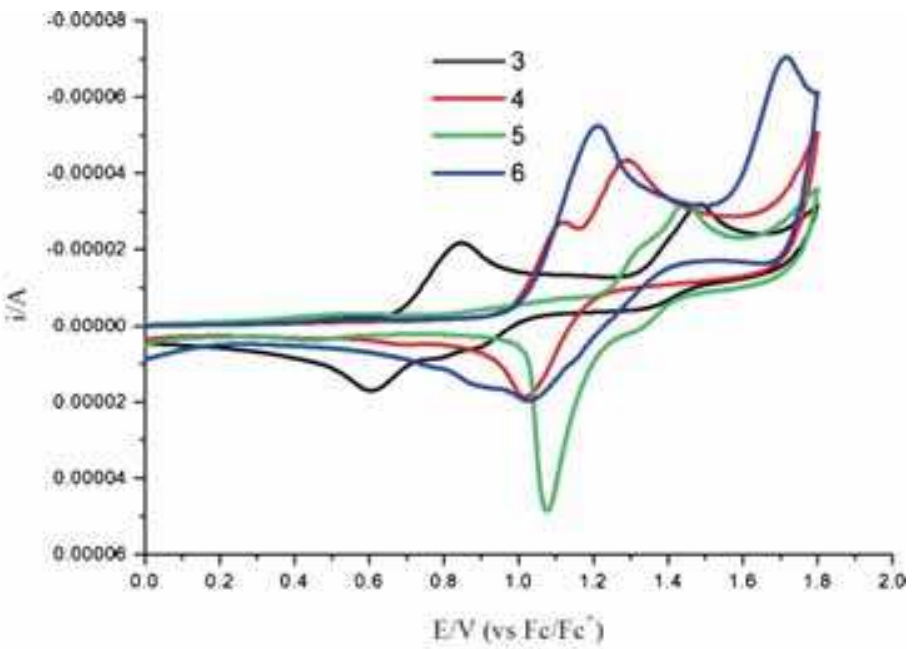

(b)

Figure 2. The cyclic voltammogram (anodic sweep) of (a) compound 2, and; (b) compounds 3-6, measured in anhydrous $\mathrm{CH}_{2} \mathrm{Cl}_{2}$ solution against ferrocene/ferrocenium at $100 \mathrm{mV} / \mathrm{sec}$.

Table 3. Electrochemical and thermal data of compounds 2-6.

\begin{tabular}{lcccccccc}
\hline Compd & $E_{\text {ox }}^{\text {peak }}$ & $E_{\text {red }}^{\text {peak }}$ & $\mathrm{HOMO}^{\mathrm{c}}$ & $\mathrm{LUMO}^{\mathrm{d}}$ & $E_{g}^{E C \mathrm{e}}$ & $\mathrm{T}_{\mathrm{d}}\left({ }^{\circ} \mathrm{C}\right)^{\mathrm{f}}$ & $\mathrm{T}_{\mathrm{m}}\left({ }^{\circ} \mathrm{C}\right)^{\mathrm{g}}$ & $\mathrm{T}_{\max }\left({ }^{\circ} \mathrm{C}\right)^{\mathrm{h}}$ \\
\hline 2 & $1.139,1.338$ & -1.497 & -5.38 & -2.93 & 2.44 & $277(385)$ & 249 & 571 \\
3 & $0.848,1.492$ & -1.556 & -5.11 & -2.85 & 2.25 & $355(442)$ & 263 & 575 \\
4 & $1.116,1.294$ & -1.520 & -5.39 & -2.89 & 2.50 & $292(423)$ & 342 & 593 \\
5 & $1.331,1.439$ & -1.547 & -5.60 & -2.77 & 2.82 & $207(268)$ & 314 & 582 \\
6 & $1.211,1.715$ & -1.627 & -5.44 & -2.81 & 2.62 & $200(348)$ & 225 & 584 \\
\hline
\end{tabular}

${ }^{\mathrm{a}} E_{\text {ox }}^{\text {peak }}$ oxidation peak potential (V).

${ }^{\mathrm{b}} E_{\text {red }}^{\text {peak }}$ reduction peak potential $(\mathrm{V})$.

${ }^{\mathrm{c}} \mathrm{HOMO}$ energy level calculated from $\mathrm{E}_{\mathrm{HOMO}}=-\left[E_{o x}^{\text {peak }}-\mathrm{E}_{\mathrm{redox}}\left(\mathrm{Fc} / \mathrm{Fc}^{+}\right)+4.8\right] \mathrm{eV}$.

${ }^{\mathrm{d}} \mathrm{LUMO}$ energy calculated from $\mathrm{E}_{\mathrm{LUMO}}=-\left[E_{\text {red }}^{\text {peak }}-\mathrm{E}_{\text {redox }}\left(\mathrm{Fc}_{\mathrm{Fc}}{ }^{+}\right)+4.8\right] \mathrm{eV}$.

${ }^{\mathrm{e}} E_{g}^{E C}$ calculated from $E_{g}^{E C}=[\mathrm{HOMO}-\mathrm{LUMO}] \mathrm{eV}$.

${ }^{\mathrm{f}}$ Decomposition temperature at $5 \%$ and $10 \%$ (in parentheses) weight loss in TGA.

g Melting point determined by open capillary method

${ }^{\mathrm{h}}$ Derivative weight loss. 


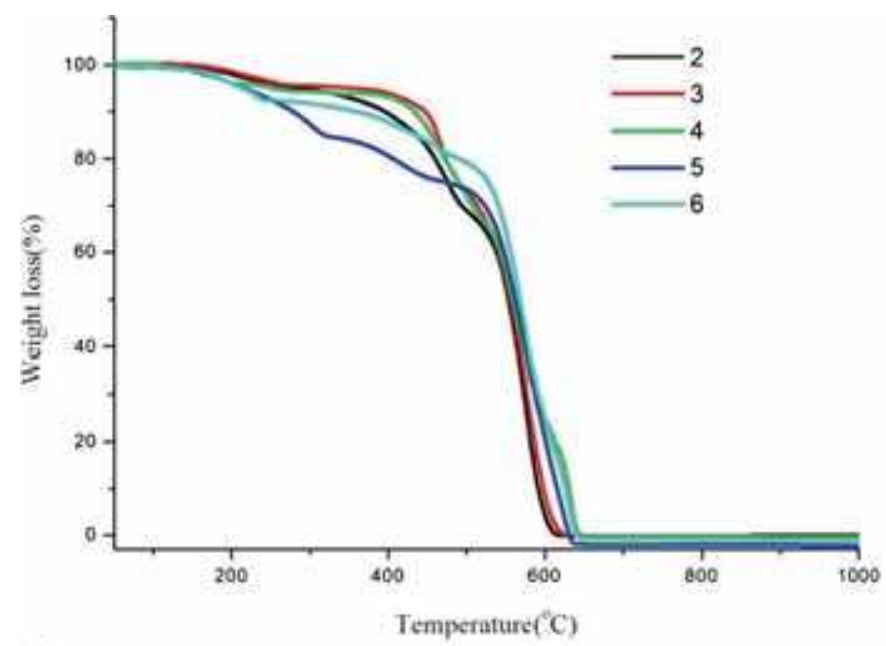

(a)

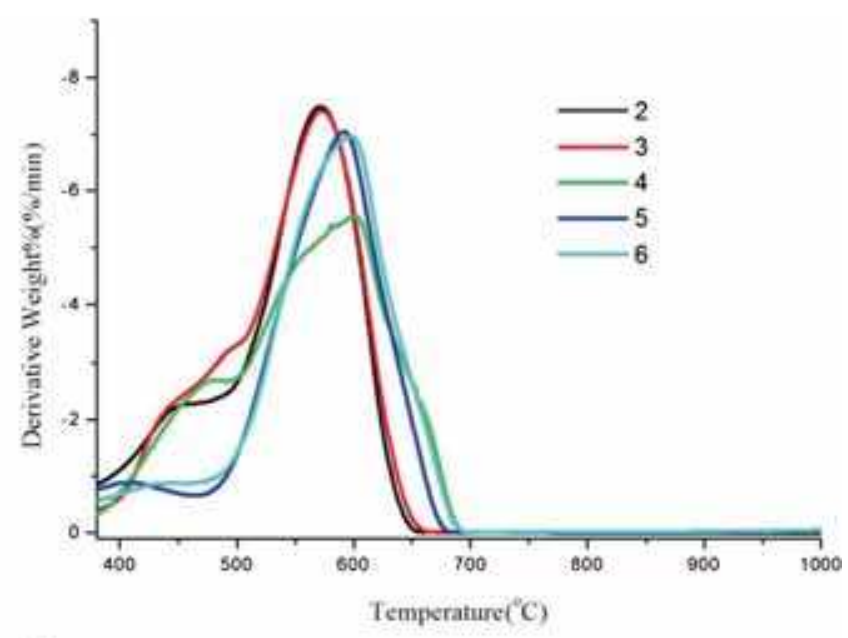

(b)

Figure 3. (a) TGA thermogram and (b) and Derivative weight loss of compounds 2-6 under nitrogen atmosphere at normal pressure. Heating rate, $10^{\circ} \mathrm{C} / \mathrm{min}$.

analysis (TGA) and Differential Thermal Analysis (DTA).

TGA thermogram (figure 3a) of compounds 2-6 reveals that these derivatives have high thermal stability with no weight loss at low temperature and are comparable to the commonly used hole-transporting materials such as 9,10-bis(diphenylamino)anthracene (PPA), 9, 10-bis(1-napthylphenylamino)anthracene (NPA), TPD, 4,4'-bis(1-naphthylphenylamino)biphenyl (NPB) with stability in range $185-382^{\circ} \mathrm{C} .{ }^{51,52}$ The decomposition temperature corresponding to $5 \%$ and $10 \%$ weight losses were in the range of $200-355^{\circ} \mathrm{C}$ and $268-442^{\circ} \mathrm{C}$, respectively. The order of thermal stability among the synthesized derivatives is $\mathbf{3}>\mathbf{4}>\mathbf{2}>\mathbf{5}>\mathbf{6}$. Melting points of the derivatives 2-6 are in the range of $225-342^{\circ} \mathrm{C}$. The derivative TGA plot (figure $3 \mathrm{~b}$ ) shows narrow derivative peak, indicating high decomposition temperature with $\mathrm{T}_{\max }$ in the range of $571-593^{\circ} \mathrm{C}$. The sharp endothermic peak is observed for all compounds in the DTA plot (see supplementary information) at their respective melting points and exothermic peak is observed above $500^{\circ} \mathrm{C}$ for all the synthesized molecules suggesting that no crystallization is taking place upto $500^{\circ} \mathrm{C}$.

\section{Conclusions}

Triarylamines based on benzo[ $g]$ quinoxaline compounds have been synthesized via palladium-catalyzed $\mathrm{C}-\mathrm{N}$ bond formation reaction using $\mathrm{Pd}_{2}(\mathrm{dba})_{3} /$ SPhos catalyst system in good yields. The absorption, emission, electrochemical and thermal properties of the synthesized materials are significantly influenced by the nature of the peripheral amine segments attached to the benzo $[g]$ quinoxaline core. The emission colour of these materials was tuned from green to yellow by changing the nature of the diarylamines. The electrochemical investigation of the synthesized molecules shows that the ionization potentials and electron affinities are comparable to the most commonly used hole-transporting materials. Thermal properties revealed that the derivatives have high melting point and good thermal stability. The results indicate that the synthesized molecules are promising candidates for hole transporting application in organic electronics.

\section{Supplementary Information}

All additional information pertaining to compounds 2-6, namely, absorption and emission spectra in $\mathrm{CH}_{2} \mathrm{Cl}_{2}, \mathrm{CHCl}_{3}$ and solid thin films (figures $\mathrm{S} 1$ and $\mathrm{S} 2$ ), Chromaticity diagrams (figures S3), Cyclic voltammograms (cathodic sweep) (figures S4 and S5), DTA plot (figure S6), HRMS spectra (figure S7), FTIR spectra (figure S8), ${ }^{1} \mathrm{H}$ and ${ }^{13} \mathrm{C}$ NMR spectra (figures S9 and S10), Photographs (figures S11 and S12) are given in the supporting information. Supplementary Information is available at www.ias.ac.in/chemsci.

\section{Acknowledgements}

The authors are greatly thankful to Micro-Analytical Laboratory, Department of Chemistry, and University of Mumbai for providing Instrumental facilities. One of the authors (Azam M. Shaikh) is grateful to University Grants Commission, India for providing Junior Research Fellowship. 


\section{References}

1. Tang C W and VanSlyke S A 1987 Appl. Phys. Lett. 51 913

2. Burroughes J H, Bradley D D C, Brown A R, Marks R N, Mackay K, Friend R H, Burns P L and Homes A B 1990 Nature 347539

3. Friend R H, Gymer R W, Holmes A B, Burroughes J H, Marks R N, Taliani C, Bradley D D C, dos Santos D A, Brédas J L, Lögdlund M and Salaneck W R 1999 Nature 397121

4. Baldo M A, Thompson M E and Forrest S R 2000 Nature $\mathbf{4 0 3} 750$

5. Wong K-T, Chien Y-Y, Chen R-T, Wang C-F, Lin Y-T, Chiang H-H, Hsieh P-Y, Wu C-C, Chou C H, Su Y O, Lee G-H and Peng S-M 2002 J. Am. Chem. Soc. 124 11576

6. Facchetti A, Yoon M-H, Stern C L, Katz H E and Marks T J 2003 Angew. Chem. Int. Ed. 423900

7. Yang L, Ren A-M, Feng J.-K, Liu X-D, Ma Y-G and Zhang H-X 2004 Inorg. Chem. 435961

8. Anthony J E 2008 Angew. Chem. Int. Ed. 47452

9. Imahori H, Umeyama T and Ito S 2009 Acc. Chem. Res. 421809

10. Ning Z and Tian H 2009 Chem. Commun. 5483

11. Jenekhe S A, Liangde L and Maksudul M A 2001 Macromolecule 347315

12. Kulkarni A P, Wu P-T, Kwon T W and Jenekhe S A 2005 J. Phys. Chem. B. 10919584

13. Grabowski Z R, Rotkiewicz K and Rettig W 2003 Chem. Rev. 1033899

14. Yoshihara T, Druzhinin S I and Zachariasse K A 2004 J. Am. Chem. Soc. 1268535

15. Förster Th 1969 Angew. Chem. Intl. Ed. 8333

16. Jenekhe S A and Osaheni J A 1994 Science 265765

17. Gao Z Q, Lee C S, Bello I, Lee S T, Chen R M, Luh T Y, Shi J and Tang C W 1999 Appl. Phys. Lett. 74865

18. Gao Z Q, Lee C S, Bello I, Lee S T, Wu S K, Yan Z L and Zhang X H 1999 Synth. Met. 105141

19. Bernardo G, Esteves M A, Guerreiro A M, Gigante B and Morgado J 2008 Opt. Mater. 31320

20. Iyer A, Bjorgaard J, Anderson T and Köse M E 2012 Macromolecules 456380

21. Chandrasekaran Y, Dutta G K, Kanth R B and Patil S 2009 Dyes Pigm. 83162

22. Hirayamaa T, Yamasakia S, Amekub H, Tsutomu I, Thiemannc T and Mataka S 2005 Dyes Pigm. 67105

23. Reddy M A, Thomas A Mallesham G, Sridhar B, Rao V J and Bhanuprakash K 2011 Tetrahedron Lett. 52 6942

24. Son H-J, Han W-S, Wee K-R, Yoo D-H, Lee J-H, Kwon S-N, Ko J and Kang O S 2008 Org. Lett. 235401

25. Thomas K R J and Tyagi P 2010 J. Org. Chem. 758100

26. Jandke M, Strohriegl P, Berleb S, Werner E and Brutting W 1998 Macromolecules 316434
27. Zhang K Y, Po-Yam Li S, Zhu N, Or I W -S, Cheung M S -H, Lam Y-W and Kenneth K-W Lo 2010 Inorg. Chem. 492530

28. Unver E K, Tarkuc S, Baran D, Tanyeli C and Toppare L 2011 Tetrahedron Lett. 522725

29. Wang X, Zhou Y, Lei T, Hu N, Chen E-Q and Pei J 2010 Chem. Mater. 223735

30. Danel A, Gondek A and Kityk I 2009 Opt. Mater. 32267

31. Kim S K, Yang B, Park Y I, Ma Y J -Y and Lee H -J K 2009 Org. Electron. 10822

32. Yang B, Kim S K, Xu H, Park Y-I, Zhang H-Y, Gu C, Shen F Z, Wang C L, Liu D D, Liu X D, Hanif M, Tang S, Li W J, Li S F, Shen J C, Park J W and Ma Y-G 2008 Chem. Phys. Chem. 92601

33. Noine K, Pu Y-J and Nakayama Kido K-I 2010 Org. Electron. 11717

34. Kwon Y S, Lee K H, Young K G, Seo J H, Kim Y K and Yoont S S 2009 J. Nanosci. Nanotechnol. 97056

35. Thomas K R J, Velusamy M, Lin J T, Chuen C H and Tao Y T 2005 J. Mater. Chem. 154453

36. Jia W L, McCormick T, Liu Q D, Fukutani H, Motala M, Wang R-Y, Tao Y and Wang S 2004 J. Mater. Chem. 143344

37. Shen J-Y, Yang X-L, Huang T-H, Lin J T, Ke T-H, Chen L-Y, Wu C-C and Yeh P 2007 Adv. Funct. Mater. 17 983

38. Thomas K R J, Velusamy M, Lin J T, Tao Y T and Chuen C-H 2004 Adv. Funct. Mater. 14387

39. Huang T-H, Lin J T, Chen L-Y, Lin Y-T and Wu C-C 2006 Adv. Mater. 18602

40. Thomas K R J, Huang T-H, Lin J T, Pu S-C, Cheng Y-M, Hsieh C-C and Chou P-T 2008 Chem.-Eur. J. 14 11231

41. Thomas K R J, Lin J T, Tao Y-T and Chuen C-H 2002 Adv. Mater. 14822

42. Thomas K R J, Lin J T, Tao Y-T and Chuen C-H 2002 Chem. Mater. 142796

43. Thomas K R J, Lin J T, Tao Y-T and Chuen C-H 2004 Chem. Mater. 165437

44. Harwood L M, Moody C J and Percy J M 1999 In Experimental Organic Chemistry: Principles and Practice (Blackwell: Oxford, UK)

45. Katsuta S 1994 Chem. Lett. 1239

46. Bond A M, Henderson T L E, Mann D R, Thormann W and Zoski C G 1988 Anal. Chem. 601878

47. Hartwig J F 2006 Synlett 91283

48. Buchwald S L and Surry D S 2011 Chem. Sci. 227

49. Chiu K Y, Su T X, Li J H, Lin T-H, Liou G S and Cheng S-H 2005 J. Electroanal. Chem. 57595

50. Armand J, Boulares L, Bellec C and Pinson J 1982 Can. J. Chem. 602797

51. Yu M X, Duan J P, Lin C H, Cheng C H and Tao Y T 2002 Chem. Mater. 143958

52. Wu C, Djurovich P I and Thompson M E 2009 Adv. Func. Mater. 193157 